\title{
A CRISTIANIZAÇÃO DOS VIKINGS E DO NORTE EUROPEU
}

\author{
Vikings and Northern European Christianization
}

\author{
Johnni Langer*
}

BOYER, Régis. Le Christ des barbares, le monde nordique (IX-XIII siècle). Paris: Les Éditions Du Cerf, 1987 (coleção “Jésus depuis Jésus”). Ilustrado, 155 p.

Em sua longa história desde as raízes no Oriente Médio, o cristianismo conheceu diversas formas de ser aceito e de ser praticado enquanto religiosidade. Em especial, o norte europeu vivenciou muitos momentos inusitados de evangelização, ${ }^{1}$ seja com os Celtas das ilhas britânicas e Irlanda a partir do século $\mathrm{V}$ até o processo de conversão dos últimos pagãos da Europa, os famosos guerreiros Vikings, em meados dos séculos IX a X d.C. Vários pesquisadores já analisaram este segundo processo de conversão, mas sem dúvida é com a obra Le Christ des barbares que temos um quadro teórico e analítico muito mais profundo sobre a questão. Escrita pelo renomado historiador Régis Boyer, professor da Universidade de Paris-Sorbonne e autor de mais de 40 livros sobre vikingologia, a obra foi dividida em três capítulos, sendo o primeiro (Essai sur la mentalité religieuse des anciens Scandinaves) uma síntese analítica sobre o paganismo Viking; o segundo (La conversion du Nord) a respeito do processo histórico e social da conversão; e o terceiro (Le Christ dans le monde scandinave), as imagens e representações sobre a nova religião na Escandinávia medieval.

* Pós-Doutorando em História Medieval pela USP, bolsista da FAPESP (sob supervisão do prof. Dr. Hilário Franco Júnior). Membro do NUPPER, Núcleo Paranaense de Pesquisas em Religião e grupo Brathair de Estudos Celtas e Germânicos. <johnnilanger@yahoo.com.br>

1 Sobre a questão da cristianização do norte europeu ver: CARDOSO, Ciro Flamarion. O purgatório no mundo de Beda. Signum, n. 5, 2003, p. 47-72; CARDOSO, Ciro Flamarion. O paganismo anglo-saxão: uma síntese crítica. Brathair, v. 4, n. 1, 2004, p. 19-35 <www.brathair.com>; FRANCO JÚNIOR, Hilário. Valtário e Rolando: do herói pagão ao herói cristão. A Eva barbada: ensaios de mitologia medieval. São Paulo: Edusp, 1996. p. 159-174. 
Na introdução (Un sujet difficile a délimiter), Boyer concede os elementos metodológicos e teóricos de sua investigação. Explora o conceito polissêmico e muitas vezes anacrônico do termo "bárbaro", examina as fontes literárias autóctones e estrangeiras para o estudo da temática, concede algumas problemáticas para o exame da questão da passagem do paganismo ao cristianismo, além de algumas chaves de pronúncia para a grafia escandinava antiga. Boyer foi influenciado diretamente pelo mitólogo francês Georges Dumézil, preconizador da teoria da tripartição entre os povos de origem indo-européia. ${ }^{2}$ Outra influência, muito perceptível nesta obra em especial, é a advinda do lingüista Ferdinand de Saussure. Ambos os autores eram adeptos do estruturalismo, pelo qual percebemos a importância que Boyer concede desde a análise de palavras da língua nórdica para entender certos conceitos religiosos, como aspectos do cotidiano para refletir estruturas sociais mais genéricas. Assim, o investigador utilizou desde manuscritos antigos, documentos eclesiásticos e fontes iconográficas, para compreender o fenômeno da transição religiosa do mundo nórdico, sempre percebendo estas fontes dentro de um contexto estruturalista.

O paganismo nórdico, investigado no primeiro capítulo, é uma das especialidades de Régis Boyer, ${ }^{3}$ sendo definido basicamente como uma religiosidade profundamente rural, realista e pragmática e que concedia um espaço privilegiado para a magia fatídica. ${ }^{4}$ Os locais de culto eram quase sempre em locais abertos (cachoeiras, lagos, florestas), sempre focalizados no culto aos ancestrais. Por essa razão os mortos eram enterrados próximos às residências das famílias. Não existia sacerdócio profissional, sendo os chefes de famílias e os reis os executores dos principais rituais públicos. A morte não era jamais considerada um termo absoluto ou ruptura radical, mas antes considerada uma simples mudança de estado. A alma era conce-

2 Para Georges Dumézil, as sociedades indo-européias (gregos, romanos, hindus, celtas, germanos, eslavos, etc) seriam organizadas socialmente em três ordens: a dos soberanos, a dos guerreiros e a dos trabalhadores. Esse esquema também seria refletido nas estruturas mitológicas e religiosas. Conf. DUMÉZIL, Georges. Mythes et dieux des germains: essai d’interpretátion comparative. Paris: Librairie Ernest Leroux, 1939. p. 12.

3 Entre as suas várias obras publicadas, destacamos Yggdrasill: la religion des anciens Scandinaves. Paris: Payot, 1981 e Le monde du Double: la magie chez les anciens Scandinaves. Paris: Berg International, 1986.

4 Para uma abordagem geral em português sobre a religiosidade na Escandinávia medieval pré-cristã consultar: LANGER, Johnni. Religião e magia entre os Vikings: uma sistematização historiográfica. Brathair, v. 5, n. 2, 2005, p. 55-82. Disponível em: <www.brathair.com> 
bida como sendo ao mesmo tempo individual e coletiva, sobrevivendo pela reencarnação na própria família do clã. A magia fatídica era cultuada com funções divinatórias e sacrificiais. Por meio dela era possível, segundo as crenças nórdicas, contatar o mundo sobrenatural dos mortos e obter conhecimento sobre o futuro ou sobre como resolver os problemas cotidianos. $\mathrm{O}$ destino (ørlög) já seria determinado previamente, seguindo uma tradição germânica muito antiga, a fatalidade dos deuses, algo que depois foi recuperado artisticamente com as óperas oitocentistas de Richard Wagner.

Ainda neste capítulo, Boyer analisa algumas estruturas comuns ao paganismo nórdico e ao cristianismo, como a questão do rei sagrado, a união mística entre os soberanos terrestres e as forças celestiais, calendário ritualístico e o sacerdócio. Todos estes elementos vão colaborar com a futura conversão da Escandinávia, algo que Boyer trata ao final do subcapítulo (Une conversion de caractère souvent politique). Examinando algumas fontes iconográficas medievais, como esculturas em cruzes, pias batismais e figuras em alto relevo de portas e igrejas, Boyer demonstra que muitas conversões de altas personalidades das comunidades Vikings foram puramente políticas, tentando vincular-se às tentadoras economias do continente ou então como forma de estabelecer maiores vínculos entre os poderes constituídos. No próximo subcapítulo (Un grand esprit de tolérance), o autor explora outras razões da conversão, que já não foram puramente externas, mas internas ao contexto cultural nórdico. Por exemplo, o espírito de tolerância do paganismo Viking, típico das religiões politeístas, onde uma nova crença ou culto à deidade estrangeira era facilmente incorporado aos vários já existentes. Isso explica o encontro de uma estatueta de Buda (obtida por contatos comerciais) numa sepultura pagã da Suécia do século IX d.C., e a própria adesão em massa ao cristianismo em várias regiões da Escandinávia. Boyer também não deixa de comentar um aspecto enfatizado recentemente por pesquisadores, o de que o paganismo já se encontrava em declínio antes mesmo da chegada do cristianismo, vítima de conflitos internos (rivalidades de cultos e deidades ou de classes sociais) ou produto das mudanças na sociedade nórdica (de simples estruturas campesinas para grandes reinos unificados e centralizados).

No segundo capítulo, o pesquisador francês examina as condições históricas que propiciaram a conversão da Europa do Norte. Basicamente, foram duas as vias utilizadas para o processo de evangelização: uma frente estabelecida pela rota frísia e alemã, que seguiam estritamente ordens reli- 
giosas e políticas advindas de Roma; outra frente vinda do mundo de origem Celta, as ilhas britânicas e a Irlanda, com características evangelizadoras diferenciadas e com toda uma gama de arte e literatura que se fundiu com o mundo nórdico. Os métodos empregados também variaram, conforme a época e a região atingida. Podiam ser missões puramente culturais, frutos do contato entre as civilizações; outras podiam ser frentes de evangelização utilizando oradores treinados; e a terceira, o poder da espada, literalmente. Muitos reinos Vikings adotaram o cristianismo e obrigaram seus súditos a se converterem pela força, causando a morte de muitas pessoas. Em algumas situações, a passagem foi totalmente pacífica e atingiu a todos, como na Islândia, que em 999 decidiu por assembléia a conversão de toda a comunidade. Muitas vezes pagãos conviviam lado a lado com cristãos, num grande processo de tolerância.

O último capítulo é um dos mais interessantes do livro. Para Boyer, os escandinavos criaram basicamente três formas de representação de Cristo: como estrangeiro; como inimigo; adotado e reconhecido. Como estrangeiro, Cristo foi concebido a partir do referencial das estruturas familiares, o mais importante elemento de identificação social dos nórdicos. Sendo um elemento estranho a este contexto, a sua figura foi concebida em termos de ordem jurídica: externa a qualquer clã, a idéia de pacto entre forças divinas e os homens não poderia concretizar-se. Com isso, os missionários esforçaram-se para modificar esta imagem de Jesus, tornando ele um Hvíta-Krist (Cristo Branco), mais adequado ao referencial da cultura escandinava. Como inimigo, Cristo foi oposto às antigas divindades do panteão pagão, geralmente confrontado na literatura das Sagas, especialmente as escritas entre os séculos XII e XIV. Sendo um poderoso rei dos céus com sua hirð (guarda) de anjos - no referencial da literatura mencionada -, Cristo deveria cumprir a antiga função que os deuses mantinham no mundo Viking: combater a fome e todo problema cotidiano, perpetuar a lei e a ordem, criar um referencial modelar tanto de comportamento quanto de ética, perpetuar o equilíbrio e a ordem do universo. Neste sentido, quando Cristo surge em duelo com divindades pagãs, especialmente o deus Pórr (Thor, o mais cultuado de toda Escandinávia), e vence de alguma forma ou de outra, foi um demonstrativo tanto da superioridade do cristianismo quanto de uma necessidade de substituir uma forma religiosa por outra que atendesse os anseios sociais e simbólicos das comunidades. Isso fica bem claro com a 
perpetuação de práticas totalmente pagãs, como a elaboração de runestones (estelas rúnicas) pelos cristãos. Agora ao lado de igrejas ou convertidas em lápides de cemitérios, elas cumprem seu papel de permitir aos indivíduos mais ricos serem inseridos na memória da coletividade. Essa mesma importância concedida às runas ${ }^{5}$ também é analisada pelo autor na terceira representação escandinava, a do Cristo adotado e reconhecido. A quantidade de fórmulas mágicas utilizando runas após a introdução do cristianismo foi muito grande. Elas conviviam com esculturas e decorações pagãs no interior de igrejas de madeira, especialmente da Noruega, ${ }^{6}$ ou então como amuletos utilizados individualmente. Para Boyer, a sobrevivência destas práticas surgiu da necessidade que os escandinavos tinham de terem ligação com o sobrenatural, algo que a realização dos cultos cristãos não conseguia atender plenamente.

Como conclusão, o historiador investiga o contexto de Cristo identificado como drengr góðr (deus excelente). Ele acabou encarnando os antigos ideais tão valorizados pelos Vikings: um homem reputado por seu comportamento heróico, digno de uma Saga.

A leitura da obra é indicada não somente para os estudiosos da história do cristianismo e das religiões, mas a todos os que têm interesse pela Idade Média e seu potencial em fornecer indicações de nossa herança espiritual, material e cultural.

5 As runas (mistério, em nórdico antigo) são uma forma de alfabeto que foi utilizado eventualmente para processos mágico-religiosos, como atos de cura, adivinhação, magias de maldição, etc. Conforme LANGER, Johnni. Deuses, monstros, heróis: ensaios de mitologia e religião Viking. Brasília: Universidade de Brasília/UNB (no prelo).

6 Existem dezenas de igrejas de madeira do século XII e XIII na Noruega, preservadas até hoje, que contêm cenas mitológicas (como o dragão Fafnir e o herói Sigurd), representações de divindades (como o deus Óðinn, Odin, e as valquírias), além de elementos estéticos ainda do período pagão. As motivações da sobrevivência destes elementos pagãos em espaços sagrados do cristianismo ainda são motivo de muita polêmica. Conf. LANGER, Johnni, op. cit. 